\title{
Usando o programa sobre equilíbrio químico "Le Chat"
}

Muito do software educativo que os professores têm ao seu dispor não é, por si só, "auto-suficiente", necessitando de elementos que o contextualizem em situações e objectivos pedagógicos concretos.

Os roteiros de exploração surgem como importantes materiais de apoio à exploração de peças de software educativo. Perante uma multiplicidade de opções possíveis é fundamental fornecer ao aluno pistas e indicações para que o caminho percorrido, embora personalizado e construído pelo próprio, gere aprendizagens significativas.

O presente artigo apresenta um roteiro de exploração sobre uma simulação de equilíbrio químico, o programa "Le Chat II".

\section{Roteiros de exploração - elos de ligação entre o software educativo e a realidade pedagógica}

Os alunos que se encontram actualmente a frequentar as escolas básicas e secundárias do século XXI são frequentemente alcunhados por zap generation. A zap generation está habituada à "acção", isto é, a sua vida é um verdadeiro zapping - fazem zapping entre as dezenas de canais de televisão de modo a assistirem ao seu programa favorito, trocam SMS constantemente, saltam para o computador, onde acedem ao e-mail, surfam na net recolhendo dados para os trabalhos e comunicam em salas de chat. Programam o seu tempo para as mais diversas actividades, algumas das quais simultâneas "clicando aqui e ali sem parar".

Quando estão perante uma peça de software educativo a sua atitude não é diferente. Assim, é apresentado ao professor mais um desafio pedagógico - travar os "cliques" sucessivos dos alunos perante os programas educativos. Além

\footnotetext{
${ }^{1}$ Faculdade de Ciências da Universidade do Porto

${ }^{2}$ Centro de Física Computacional da Universidade de Coimbra
}

do papel multifacetado que o professor já tem, há que integrar em termos didácticos as Tecnologias da Informação e Comunicação (adiante TIC). É da responsabilidade do professor a forma como os alunos exploram os programas educativos que se the apresentam no computador. É neste contexto que os roteiros de exploração se podem revelar um instrumento muito valioso, senão mesmo indispensável, pois podem ser entendidos como uma ferramenta que enriquece a aplicação pedagógica das TIC junto dos alunos.

Os roteiros de exploração têm como principal objectivo estreitar a relação entre as peças de software educativo e os objectivos de aprendizagem que se pretendem desenvolver. Desta forma, deverão ser meios para fomentar no aluno o gosto pela pesquisa, pela reflexão, pela participação activa na construção do conhecimento e, acima de tudo, pelo acto de aprender [1]. O trabalho que propomos utiliza uma linguagem simples e adequada aos alunos, tendo sempre presente o rigor científico, e uma referência aos objectivos que regem a proposta.

As características dos roteiros denotam uma aparente contradição entre o comportamentalismo e o construtivismo.
Mas cabe ao professor a tarefa, difícil, mas desafiante, de conseguir a fusão feliz entre os dois pólos, isto é, ele deve conseguir o justo equilíbrio entre movimentos mais dirigistas e mais auto-construídos por parte dos alunos [2]. O "segredo" poderá estar em conseguir encontrar o meio-termo entre a liberdade construtivista e a mínima orientação, permitindo ao aluno usufruir de forma enriquecedora das TIC, travando os "cliques" frenéticos e fomentando uma exploração mais atenta dos recursos.

Indicamos de seguida o software usado no roteiro, os objectivos versados no trabalho e as legendas com as principais funções de cada uma das aplicações [3].

\section{Objectivos}

- Associar estado de equilíbrio dinâmico ao estado de equilíbrio de um sistema, em que a rapidez de variação de uma dada propriedade num sentido é igual à rapidez de variação da mesma propriedade no sentido inverso.

- Identificar equilíbrio químico como um estado de equilíbrio dinâmico.

- Interpretar gráficos que traduzem a variação da concentração em função 
do tempo, para cada um dos componentes de uma mistura reaccional.

- Identificar a reacção de síntese do amoníaco como um exemplo de um equilíbrio homogéneo quando em sistema fechado.

- Escrever as expressões matemáticas que traduzem a constante de equilíbrio em termos de concentração $(K c)$.

- Verificar, a partir de tabelas, que Kc depende da temperatura, havendo portanto, para diferentes temperaturas, valores diferentes de $K c$ para o mesmo sistema reaccional.

- Traduzir quociente de reacção, Qc através de expressões idênticas às de $K c$ em que as concentrações dos componentes da mistura reaccional são avaliadas em situações de não equilíbrio (desequilíbrio).

- Comparar valores de Qc com valores conhecidos de Kc para prever o sentido da progressão da reacção relativamente a um estado de equilíbrio.

- Relacionar a extensão de uma reacção com os valores de $K c$ dessa reacção.

- Utilizar os valores de $K c$ da reacção no sentido directo e $K^{\prime} c$ da reacção no sentido inverso, para discutir a extensão relativa daquelas reacções.

- Referir os factores que podem alterar o estado de equilíbrio de uma mistura reaccional (temperatura, concentração e pressão) e que influenciam o sentido global de progressão para um novo estado de equilíbrio.
- Prever a evolução do sistema reaccional, através de valores de $K c$, quando se aumenta ou diminui a temperatura da mistura reaccional para reacções exoenergéticas e endoenergéticas.

- Identificar a lei de Le Châtelier como a lei que prevê o sentido da progressão de uma reacção por variação da temperatura, da concentração ou da pressão da mistura reaccional.

- Reconhecer que o papel desempenhado pelo catalisador é o de aumentar a rapidez das reacções directa e inversa, para se atingir mais rapidamente o estado de equilíbrio (aumento da eficiência), não havendo, no entanto, influência na quantidade de produto obtida.

\section{Simulação educativa em Equilíbrio Químico - "Le Chat II"}

\section{Contextualização curricular}

O programa "Le Chat II" - Simulações em Equilíbrio Químico - consiste basicamente numa ilustração no computador, de forma gráfica, do fenómeno do equilíbrio químico (associado ao portal "mocho" em www.mocho.pt/search/ local.php?info=local/software/quimica/ lechat2.info ).

Pretende-se, em particular, visualizar as alterações produzidas em sistemas químicos gasosos por alterações de concentrações de reagentes ou produtos, temperatura do sistema ou pressão (volume) a que o sistema está sujeito, em conformidade com o Princípio de Le Châtelier. O programa, bem como o "Roteiro de Exploração" que se apresenta de seguida, destina-se essencialmente a alunos do $11 .^{\circ}$ ano de escolaridade, podendo ser usado, contudo, em jeito diagnóstico ou revisional, por alunos do 12. ${ }^{\circ}$ ano ou mesmo do primeiro ano do Ensino Superior.

"O conceito de equilíbrio químico, eventualmente pelo seu carácter abstracto e pela exigência do domínio de um largo número de outros conceitos químicos, tem-se revelado de difícil compreensão, sendo elevado o número de concepções alternativas identificadas e referenciadas em literatura do âmbito da Didáctica da Química. De entre as concepções (cerca de vinte) que, marcadamente, os alunos evidenciam, destaca-se a visão estática do equilíbrio químico (nenhuma reacção ocorre), a visão compartimentada do equilíbrio (sistema constituído por dois compartimentos individualizados para as reacções directa e inversa), a igualdade de concentrações de reagentes e de produtos na situação de equilíbrio, o recurso a modelos híbridos (cinético e termodinâmico) para interpretação dos valores da constante de equilíbrio e ainda a generalização inadequada da aplicação da lei de Le Châtelier" [4].

Na elaboração do "Roteiro de Exploração" são, de alguma forma, seguidas as linhas de força apontadas anteriormente sobre roteiros de exploração de software em Química.

Uma das potencialidades deste programa é a possibilidade de colocar os alunos em interacção usando um roteiro de exploração que é parte integrante do programa. O programa possui um editor de roteiros que permite aos professores

\section{Como explorar o "Le Chat II"?}

A interface de interacção inicial apresenta uma barra de menus e vários comandos que permitem explorar todas as potencialidades desta aplicação.

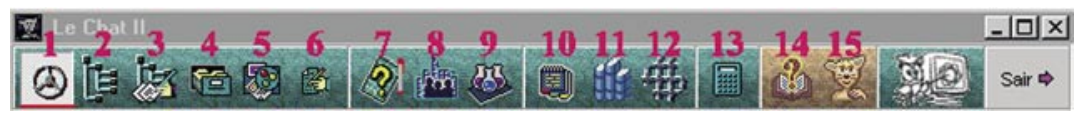
7 - Testes de Múltipla Esco- Iha
8 - Equilíbrio Químico e So- ciedade
9 - Equilíbrio Químico e La- boratório
10 - Pressupostos

2 - Roteiros de Exploração

3 - Editor de Roteiros

4 - Dados Numéricos

6 - Editor de Texto
11 - Bibliografia

12 - Ligação à Rede

13 - Calculadora

14 - Hipertextos

15 - Informação sobre o

Programa 


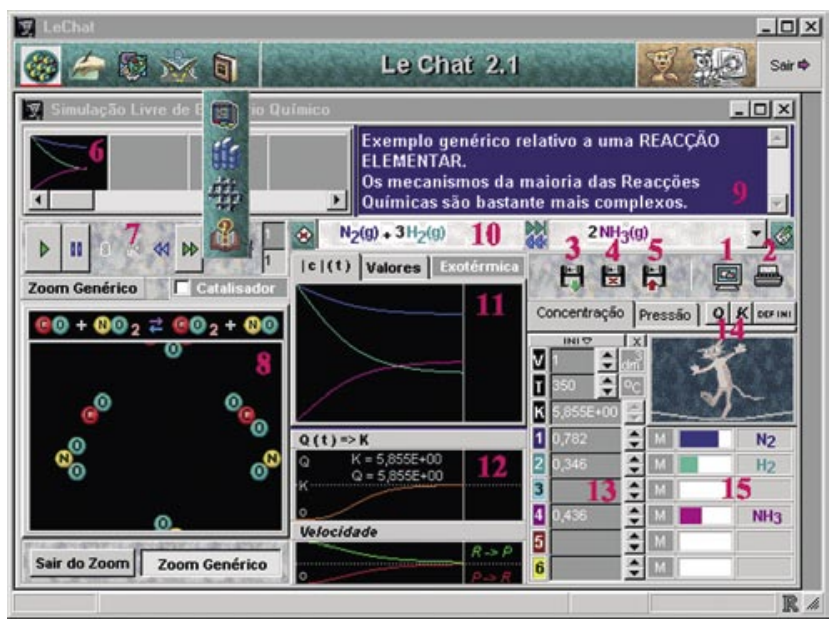

1 - Simulação Livre

2 - Roteiros de Exploração

3 - Editor de Roteiros

4 - Dados Numéricos

5 - Intervalo Lúdico

6 - Editor de Texto

7 - Testes de Múltipla Escolha

8 - Equilíbrio Químico e Sociedade

9 - Equilíbrio Químico e Laboratório

10 - Pressupostos

11 - Bibliografia

12 - Ligação à Rede
13 - Calculadora

14 - Hipertextos

15 - Informação sobre o

Programa editarem os seus próprios roteiros sem terem de dominar qualquer técnica de programação.

Podem ser vistos na Internet vários exemplos de roteiros de exploração, em diversas áreas do ensino da química, ainda que se tratem de propostas testadas com alunos mas não publicadas ainda [5]. Estes roteiros, como outros múltiplos recursos, também de química, estão acessíveis a partir do portal de ciência www.mocho.pt. O programa "Le Chat II" já foi testado por bastantes professores, tendo tido resultados proveitosos [6]. A versão inglesa deste programa, mais recente, tem igualmente disponíveis variados roteiros, quer para o ensino secundário, quer para o ensino superior $[7,8]$.

Bibliografia

[1] J.C. Paiva, L.A. Costa. Roteiros de Exploração-valorização pedagógica de software educativo de Química. QUIMICA 96 (2005) 64-66.

[2] J.C. Paiva, "Fusão Feliz", QUÍMıCA 92 (2004) 57-58.

[3] F.B. Ferreira, J.C. Paiva, "Roteiros de exploração com Tabelas Periódicas digitais", QUÍMICA 96 (2005) 67-68.

[4] Programa de Física e Química A 11 . $^{\circ}$ ano. [online] [consult 02-11-2005]. Disponível em www.iie.min-edu.pt/ programs/progrec_eh.asp
[5] Roteiros de exploração no Mocho. [online] [consult 02-11-2005].

Disponível em www.mocho.pt/Ensino/ recursos/Roteiros_de_Exploracao.

[6] M.A. Ramos, P. Louçã, J.P. Amador e Leal, "Análise do Programa "Le Chat 2", QUÍMICA 80 (2001).

[7] J.C. Paiva; Gil, V.M.S. and Correia, A.F. Le Chat: simulation in Chemical Equilibrium. Journal of Chemical Education. 79 (2002) 640-641.

[8] J.C. Paiva; Gil, V.M.S. and Correia, A.F. Le Chat: simulation in Chemical Equilibrium: A Software Program Included in Advanced Chemistry Collection. Journal of Chemical Education 80 (2003) 111.

\section{Actualidades Científicas}

\section{Nanotubos Super Elásticos}

Os nanotubos de carbono de parede simples (SWNT) continuam a surpreender os cientistas com as suas propriedades maravilhosas. De acordo com um trabalho recente, os nanotubos a elevadas temperaturas, tornam-se muito dúcteis, podendo ser esticados até mais de 3 vezes o seu comprimento original, estreitando o seu diâmetro por um factor de 15, antes de quebrarem (Nature 439 (2006) 281).

Devido à sua forte rede estrutural de ligações carbono-carbono, os SWNT são extraordinariamente resistentes e rígidos à temperatura ambiente. Teoricamente, a temperaturas normais de operação é possível esticar os SWNT em cerca de $20 \%$ do seu comprimento original, mas, experimentalmente, apenas se conseguiu esticar $6 \%$ do seu comprimento original.

Os Professores Jianyu Huang e Zhifeng Ren, o estudante Shuo Chen e colaboradores do Boston College, ficaram surpreendidos ao descobrir que os SWNT podiam ser esticados para mais do triplo do seu comprimento original, quando sujeitos a uma elevada corrente eléctrica. Um dos nanotubos, por exemplo, esticou de $24 \mathrm{~nm}$ para $91 \mathrm{~nm}$, tendo sido acompanhado por um decréscimo do seu diâmetro de $12 \mathrm{~nm}$ para $0.8 \mathrm{~nm}$.

Os investigadores atribuem a super elasticidade observada às elevadas temperaturas (aproximadamente $2000{ }^{\circ} \mathrm{C}$ ) que os SWNT atingem quando sujeitos a uma corrente eléctrica. Uma vez que os SWNT se tornam muito dúcteis a temperaturas extremas, poderão ser úteis como materiais de reforço em cerâmicas e nanocompósitos usados em aplicações a elevadas temperaturas. (adaptado de Chemical \& Engineering News 84 (4), 2006).

Helder Gomes 
A TA INSTRUMENTS é lider mundial em reologia com uma focagem sem paralelo na indústria e investigação.

o compromisso com a inovação é comprovado; o desejo de fazer medidas reológicas melhor do que os seus concorrentes comprova-se pelos contínuos avanços nos seus diferentes produtos. A aquisição da firma Rheometrics permite a oferta de todos os tipos de sistemas existentes no mercado, desde sistemas operando a tensão controlada como sistemas operando a deslocamento controlado. O modelo AR 2000 é o equipamento mais vendido no mercado. Esta unidade possui capacidades de medição sem comparação e um conjunto de acessórios único. Entre outras, podem citar-se:

- Motor de arrastamento, modelado permitindo uma vasta gama linear de torções

- Inércia de baixo valor para o melhor controle de tensão e deslocamento

- Controle directo da tensão e oscilação em toda a gama de trabalho do equipamento

- Desenho ultra robusto do corpo do equipamento

- Transdutor de força manual separado

- Electrónica isolada do resto do equipamento

- Sistemas periféricos de troca rápida e identificação automática (Smart Swap)

- Representação em tempo real da forma de onda em oscilação

- O único sistema de tensão controlada disponível num corpo único de alumínio

\section{UM Nível SUPERIor EM CALORIMETRIA}

A TA Instruments fabrica diversos tipos de equipamentos na área da calorimetria. Para além dos calorímetros de varrimento, fornece também equipamento de análise termogravimétrica, equipamentos combinados de DSC/TG, DMA e TMA. O DMA Q800 é o estado da arte em análise dinâmico/mecânica.

A unidade utiliza uma tecnologia semelhante à dos reómetros, de atrito reduzido.

$O$ deslocamento é medido utilizando um descodificador óptico que proporciona elevada sensibilidade e resolução. A unidade é utilizada na caracterização de propriedades viscoelásticas de vários tipos de materiais sólidos e é ideal para aplicações em materiais de forte resistência incluindo compósitos.

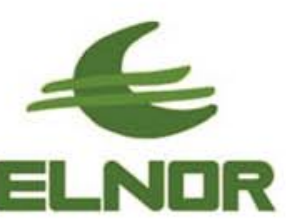

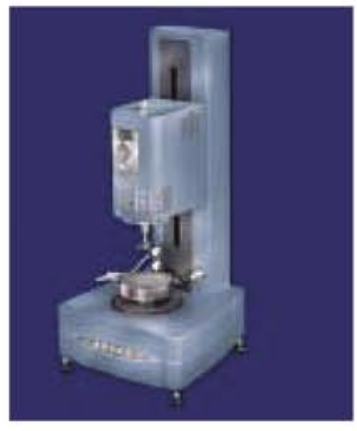

\section{TECNOLOGIA T T PARA CALORIMETRIA DIFERENCIAL DE VARRIMENTO (DSC)}

Um desenho superior para desempenhos de alto nível. $\mathrm{O}$ novo sensor $\mathrm{T}_{0}$ melhora a resolução em $300 \%$ comparativamente aos sistemas

tradicionais.

A estabilidade da

linha de base e a sensibilidade

melhoram de uma ordem de magnitude em relação também aqueles sistemas. A possibilidade de automação dá ao utilizador resultados rápidos, reprodutíveis e exactos.

A utilização do chamado DSC modulado, torna a análise dos dados. ainda mais simples, trazendo mais luz à análise de alguns eventos de difícil interpretação.

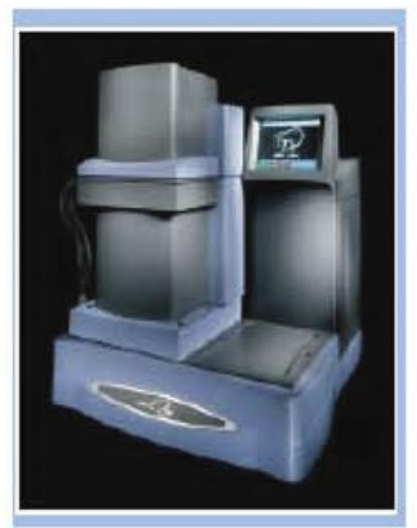

ELNOR - Equipamentos Técnicos e de Laboratório, S.A.

B R.D.Frei Jerónimo de Brito e Melo № 835 • 4465-642 LEÇA DO BALIO • PORTUGAL

$\triangle$ P.O.Box $1019 \bullet 4470$ MAIA CODEX • PORTUGAL

- Phone: (351 22) 9050400

- Fax : (351 22) 9050499 